\title{
LOS LÍMITES DE LA LITERATURA Y LA POLÍTICA: LEAVING THE ATOCHA STATION DE BEN LERNER
}

\author{
Adriana Kiczkowski \\ Universidad Nacional de Educación a Distancia
}

\section{RESUMEN}

Leaving the Atocha Station es la primera novela del escritor norteamericano Ben Lerner. Es una narración en primera persona del año que pasó en Madrid Adam Gordon, un joven poeta de Estados Unidos que consiguió una beca para desarrollar una investigación sobre las representaciones literarias de la Guerra Civil espańola. En la novela, basada en las propias experiencias de Lerner en España, se presenta la perspectiva de un viajero sobre un acontecimiento global como el ataque terrorista del 11 de marzo de 2004 en Madrid y sus repercusiones locales, teniendo en cuenta el recuerdo de la experiencia del 11 de septiembre de 2001; y plantea una reflexión sobre la relación entre literatura y política mediante un juego narrativo que se mueve entre el trabajo poético y la realidad. Adoptando un planteamiento crítico respecto a la literatura post-9/11, Lerner propone una radical desmitificación del papel político de la literatura y del arte y, destacadamente, plantea dudas sobre la supuesta obligación de ofrecer una respuesta inmediata desde la esfera artística a un determinado acontecimiento histórico, con lo que presenta un desafío importante a la relevancia política del trabajo artístico. Los ecos de un acontecimiento global como el ataque terrorista se entretejen con sus repercusiones sociales en una manifiesta perspectiva "glocal».

Palabras Clave: Ben Lerner, 11-M, literatura y política, escritores norteamericanos en España, glocalización.

THE LIMITS OF LITERATURE AND POLITICS: LEAVING THE ATOCHA STATION BY BEN LERNER

\section{Abstract}

Leaving the Atocha Station is Ben Lerner's first novel. It is a first-person narration of a year spent in Madrid by Adam Gordon, a young poet from the United States given a Fulbright Scholarship to carry out a project on literary representations of the Spanish Civil War. The novel, based on Lerner's own experiences in Spain, presents a traveler's point of view on a global event such as the terrorist attack of March 11, 2004 in Madrid and its local repercussions with the memory of the recent experience of $9 / 11$ in mind; it also reflects on the relationship between literature and politics, a narrative game that moves between poetry and reality. Taking a critical stance with post- $9 / 11$ literature, Lerner proposes a radical demystification of the political role of literature and art and, above all, expresses serious doubts about the supposed obligation of offering an immediate response to an historic event from the artistic sphere; he even challenges the political usefulness of the artistic work. A clear "glocal» perspective in which both the echoes of a global event such as a terrorist attack, and its social repercussions are intertwined.

Keywords: Ben Lerner, 11-M, literature and politics, American writers in Spain, glocalisation.

DOI: http://doi.org/10.25145/j.refiull.2019.38.009 
La literatura norteamericana ha mantenido vínculos muy estrechos con la narrativa de viajes, y han sido muchos los escritores que han ido dibujando una extensa y fructífera producción literaria con el viaje como uno de sus focos narrativos. Como señala José Manuel Barrio, el viaje se conforma como «arquetipo y génesis de la literatura de ficción norteamericana: Edgar Allan Poe, Melville, Twain, Hawthorne, John Dos Passos, Scott Fitzgerald, Faulkner, Hemingway, Steinbeck» (2004: 179). En particular, el viaje a Europa, la experiencia europea y, en su caso, el regreso han contribuido a conformar parte del emergente carácter nacional norteamericano, una suerte de educación sentimental debida tanto al carácter iniciático en lo personal como a la consolidación colectiva de los propios rasgos diferenciales respecto a Europa. Lo que para los europeos supuso la literatura de viajes, las exploraciones geográficas y la búsqueda de nuevas tierras, se transforma en el caso norteamericano en la búsqueda de los orígenes, la experiencia de sociedades con una larga historia escrita, el encuentro con «la vieja Europa».

El flujo y el influjo de los viajes de ida y vuelta hacia Europa marcaron buena parte del panorama literario estadounidense. En el caso de los escritores que se encuentran con España, indudablemente destacan quienes de una u otra manera resultaron marcados por la Guerra Civil (1936-1939) y, sobre todo, la difusión que tuvieron los relatos de un destacado grupo de autores que llegaron a Espańa para apoyar y defender al gobierno legítimo de la Segunda República frente a la insurrección armada. Además de las casi tres mil personas que formaron parte de las Brigadas Internacionales, especialmente en la Brigada Abraham Lincoln, tuvo gran importancia el desembarco de un nutrido grupo de periodistas, fotógrafos y observadores de todo tipo. Como señala Robin Vogelzang, "this outpouring of poems, articles, stories, and essays by writers the world over created an immense body of Spanish Civil War literature, with short genres, especially poetry, serving as the favored literary response to the war» (2013: 141).

Los relatos de estos viajeros en tiempos de guerra han dejado una impronta y marcado un estilo en la literatura de viajes de escritores de Estados Unidos en España. La producción literaria de esa época no sólo es importante en términos cuantitativos, sino que tiene un carácter inaugural porque de alguna manera era la primera vez que se transmitía "en directo" una guerra fuera del territorio norteamericano lo que fue, además, el preludio de los muchos años posteriores llenos de conflictos internacionales que han marcado la vida y la literatura de ese país en los últimos 80 años. Los escritores que se desplazaron a España lo hicieron motivados por un compromiso de tipo político que marca una diferencia fundamental con otro tipo de viajes o relatos de viajes. Se puede hablar en ese caso de un tipo de literatura que busca una finalidad determinada, que se propone comprometer al escritor con una realidad sociopolítica incluso más allá de sus fronteras natales. Evidentemente, estamos en una época en la que el «internacionalismo» de izquierdas era una especie de valor en alza entre un determinado grupo de intelectuales.

En las primeras décadas del siglo xxi el escenario político y social se ha modificado sustancialmente respecto a la primera mitad del siglo xx, pero la discusión sobre la relación entre arte y política sigue presente y candente. Obviamente, se han modificado las formas de los viajes, las condiciones de movilidad y su presencia 
narrativa. Como ha indicado Carl Thompson (2016), la literatura de viajes ha tenido que confrontarse con un mundo crecientemente globalizado. No es que se trate de un fenómeno nuevo, aunque el concepto se ha generalizado, sobre todo, en los últimos veinticinco años en los que la interconectividad, el incremento de los viajes aéreos, internet y la mensajería instantánea pareciera que comprimen el mundo y reducen las diferencias culturales. Sin embargo, lo que está ocurriendo tal y como lo expresa Thompson es que la "globalization has unsettled, or at least complicated, the traditional binarism of 'home' and 'abroad', 'them' and 'us', that we tend to assume are fundamental to travel writing» (2016: 204). En el mismo texto el autor señala que para la mayoría de los viajeros "home» no es ya una localidad claramente identificada de la que se parte para encontrarse con un mundo más amplio, sino que más bien es un conjunto de conexiones globales, mercancías e influencias que se presentan por todas partes incluso en nuestros entornos supuestamente locales. Con ello deja entrever la importancia de analizar la nueva situación en términos de «glocalidad». El término "glocalización» emerge como un instrumento crítico que pretende comprender y especificar procesos en los que las relaciones entre lo local y lo global proceden de un entrelazamiento de acciones y determinaciones que no debieran ser consideradas unilateral o unidimensionalmente. Como he indicado en otro trabajo:

Glocalization is presented as a conceptual instrument that tries to address the complexity of contemporary societies and their multidimensionality. [...] Glocalization compels us to introduce nuances in globalization, contrary to those who are only concerned about the generalized extension of a cultural, economic or technological current that ends up covering, blurring or eliminating all the previous aspects by means of a sort of acculturation (Kiczkowski 2016: 127).

Algunas de las diferencias provocadas por estos cambios en el contexto sociopolítico en el que se produce la literatura de viajes, así como sus correspondientes tensiones, resultan particularmente notables en la novela Leaving the Atocha Station del escritor norteamericano Ben Lerner (2011), obra que podemos considerar como otra experiencia narrativa de un norteamericano en Espańa. En esta ocasión, el autor trata de ajustar cuentas tanto con el supuesto compromiso del escritor como con parte de la producción literaria de viajeros norteamericanos a la Espańa de la primera mitad del siglo xx. De hecho, ese es el anudamiento de los ejes centrales sobre los que se asienta el relato, en parte autobiográfico, que presenta Lerner en esta su primera novela. Se podría categorizar a Ben Lerner como un «Fulbright poet» del siglo XXI, siguiendo el apelativo que utiliza Diederik Oostdijk (2013) para referirse a Adrienne Rich, Richard Wilbur y John Ashbery en su estudio sobre los poetas norteamericanos en Europa en el periodo de la Guerra Fría. Lerner vive un año en Madrid, concretamente entre el 2003 y el 2004, también gracias a una beca de la Fundación Fulbright, y es en ese periodo en el que se desarrolla la trama de su novela.

Leaving the Atocha Station se interroga una y otra vez sobre el proceso creativo y el rol de los artistas frente a acontecimientos históricos de dimensiones y consecuencias tan profundas como las provocadas por la Guerra Civil española o el atentado terrorista que tuvo lugar en Madrid el 11 de marzo de 2004. La novela 
propone una desmitificación radical del papel político de la literatura y del arte y, sobre todo, expresa serias dudas sobre la supuesta obligación de ofrecer una respuesta inmediata a un evento histórico desde la esfera artística, desafiando la utilidad política del trabajo artístico, tal y como Lerner señala en una entrevista: «En Estados Unidos cada vez que ocurre algo, la reacción del mercado es inmediata, en el cine, en la literatura [...] ahora vendrá una lluvia de novelas sobre Occupy Wall Street, y así sucesivamente» (Fernández Santos 2013).

Lerner cuestiona la posibilidad de responder a la realidad desde la literatura $y$, sobre todo, se posiciona contra la necesidad de poner rótulos o demarcaciones temporales al trabajo artístico según el dictado de los acontecimientos históricos. De esta manera, en la novela se pone en entredicho la validez de las expresiones «antes de», «después de» $\mathrm{o}$ "post-», en la medida en que no se puede urgir al artista a dar una respuesta inmediata que pueda influir en el resultado de lo que acontece en la realidad. Sin embargo, la crítica que plantea Lerner respecto a la pretensión literaria de reinterpretar los hechos y, sobre todo, a la intención de que la literatura se presente como un agente de cambio social es lo que precisamente le confiere el carácter más político, tal y como expresa el propio Ben Lerner en otra entrevista concedida para el diario El Público en 2013:

En cierta forma es un libro bastante político ya que intenta retratar la sensación que uno experimenta cuando se es ciudadano de este gigantesco imperio que es Estados Unidos, así como la ansiedad que supone la búsqueda de autenticidad en el arte. [...] «Me esforcé por imaginar mis poemas o cualquier poema como herramientas capaces de cambiar las cosas ... pero no pude imaginarlo, ni siquiera pude imaginarme imaginándolo», comenta con amargura el protagonista de la novela (Losa 2013).

Leaving the Atocha Station es la primera novela de Ben Lerner, quien hasta ese momento había escrito tres libros de poesía y algunos trabajos de crítica literaria y artística. La novela es un monólogo, una narración en primera persona del año de estancia en Madrid de Adam Gordon, un joven poeta estadounidense becado por la Fundación Fulbright en el curso 2003-2004 para desarrollar una investigación sobre las representaciones literarias de la Guerra Civil española. El periodo de estancia en Madrid coincide con el momento en que el propio Ben Lerner disfrutó de esa beca en dicha ciudad, de lo que queda constancia en los múltiples componentes autobiográficos de la obra.

Adam Gordon se encuentra reiteradamente ante la encrucijada de la utilidad de la poesía, en general, y de la suya en particular. El personaje juega con el lenguaje e ironiza sobre el acto creativo, las formas de hacer poesía, el acto de escribir, lo que supone considerarse artista, cómo se refleja todo ello en su propia práctica poética. En particular, como elemento crítico y distanciador, recurre a un juego lingüístico que parte de la traducción de un poema de Lorca para proceder a la escritura de un nuevo poema de forma casi aleatoria:

I opened the Lorca more or less at random, transcribed the English recto onto a page of my first notebook, and began to make changes, replacing a word with 
whatever word I first associated with it and/or scrambling the order of the lines, and then I made whatever changes these changes suggested to me. Or I looked up the Spanish word for the English word I wanted to replace, and then replaced that word with an English word that approximated its sound (2011: 16).

Junto a la crítica de fondo a una pretendida excelencia del creador, la novela insiste constantemente en la ambigüedad de los actos comunicativos de Adam Gordon con aquellos con quienes mantiene relación en España, debido al desplazamiento del referente en los constantes tránsitos de una lengua a otra. De esta manera, refleja la debilidad de los significados, generando deslizamientos intencionales y diversos planos interpretativos que muestran la opacidad de los motivos de la propia acción para los otros. Utiliza su escaso conocimiento de español y el bajo dominio de inglés de sus interlocutores para aparentar profundidad de pensamiento; conscientemente deja frases a medio terminar dando a entender que está diciendo algo importante. Lerner parodia con este tipo de juegos lingüísticos la farsa y la frivolidad que se esconde tras la imagen tópica del artista.

Adam Gordon vive en Madrid en condiciones privilegiadas porque dispone de una beca que le permite subsistir con cierta tranquilidad desde el punto de vista económico. Su percepción de la ciudad y de sus habitantes no deja de estar estrechamente marcada por esa mirada exterior, por la visión del turista que no puede adentrarse con mayor profundidad en los recovecos de la ciudad porque eso requeriría otro tiempo diferente. La conciencia de esa condición y de sus limitaciones se refleja constantemente y se utiliza para sustentar, indirectamente, la crítica de la literatura hecha por los escritores comprometidos del siglo $\mathrm{xx}$, que seguramente no estaban comprendiendo siquiera el lenguaje del país que visitaban.

Esa visión tópica de España, sin embargo, debilita en cierta medida el carácter cáustico de su reflexión sobre la inanidad política del arte; al adoptar como punto más firme y realista de la narración la visión de tránsito y la mirada turística de Madrid se produce una reducción de la tensión narrativa al transformar en chistes simples lo que podría ser un comentario o reflexión irónica. De todas maneras, intenta convencernos de que no sigue los cánones habituales a su condición de extranjero en Madrid. Por ello procura distanciarse de los ciudadanos de su país, a los que caracteriza según unos parámetros también preconcebidos; el grupo de los que silenciosa y obedientemente apoyan la política de su gobierno, la invasión de Irak y la correspondiente guerra contra el terrorismo internacional y, por otro lado, el grupo de los que son críticos con su gobierno, e incluso se avergüenzan de pertenecer al «imperio» e intentan pasar desapercibidos en una ciudad extranjera. Adam Gordon es consciente de que él mismo pertenece a este segundo grupo, al que repudia igualmente: «Each member of this shadowy network resented the others, who were irritating reminders that nothing was more American, whatever that means, than fleeing the American, whatever that is, and that their soft version of self-imposed exile was just another of late empire's packaged tours» (2011: 49).

Es importante observar que, a pesar de la aparente desvinculación de los acontecimientos políticos, las resonancias de la guerra de Irak y, en general, de la «guerra contra el terror» emprendida por los Estados Unidos después del atentado 
del 11 de septiembre de 2001 están presentes durante toda la novela. Para Adam Gordon, el apoyo a la guerra de Irak es una condición indisolublemente asociada a todos y cada uno de los ciudadanos estadounidenses, lo quieran o no. Se presenta como el joven "progre» crítico con la política de su país; sin embargo, recibe por parte de los madrileños la crítica a dichas políticas como si fuera el directo responsable de ellas, a pesar de sus posturas críticas a las políticas de Bush.

La visión de Adam Gordon sobre España refleja y es consecuencia de un imaginario cultural construido particularmente en las últimas décadas, pero que se amalgama con antecedentes procedentes de la propia narrativa de los norteamericanos producida en torno a la Guerra Civil. España en la novela de Lerner aparece como ese lugar que se refleja en las novelas de viajeros y en los tópicos de las agencias de viajes, es decir, toros, mantilla, peineta, jamón, vino áspero y cante jondo; aunque ahora matizado por la continuidad simbólico-crítica de las imágenes de las películas de Pedro Almodóvar, a quien incluso alude de forma indirecta en algún momento de la novela. Aunque para quienes viven en Madrid pueda parecer una descripción excesivamente pegada a moldes muy corrientes, es conveniente estar atento al tono de burla o de cinismo con el que se describen muchas de estas cosas: «During the first phase of my research, I thought all Madrid slept during the siesta, and I drifted off imagining I was joining the rest of the slumbering capital, although later I learned that, of all the people I knew in Madrid, I was the only person who actually used this time to sleep" (2011: 18). Como se ve, el autor juega irónicamente con uno de los estereotipos más comunes asociados a la vagancia, al desinterés por el trabajo y el progreso que se ha atribuido históricamente al espańol por parte del extranjero.

En la novela, Madrid aparece como el sitio apropiado para que un joven de un pueblo de Kansas experimente un sinfín de emociones que le ayudarán a enriquecer su poesía. Sin embargo, esta representación es motivo de una burla permanente por su parte en la medida en que es consciente de que se trata de la caracterización tópica, ya que no son pocas las veces en la novela en las que hablará de la falsedad de la pretendida posibilidad de "experimentación» o de acumulación de experiencias vitales porque él mismo se niega a avanzar en la inmersión cultural aunque, a la vez, trate de aparentar que la está realizando: «I tried my best not to respond to most of the e-mails I received as I thought this would create the impression I was offline, busy accumulating experience, while in fact I spent a good amount of time online» (2011: 19).

La ciudad de Madrid está profundamente imbricada en la trama de la novela. El Museo del Prado, el Retiro y la plaza de Santa Ana son los tres lugares claves en el transcurso de la vida de Adam Gordon en Madrid. Va al Museo del Prado todos los días a contemplar el cuadro El descendimiento del pintor flamenco Roger Van der Weyden. El museo se erige en el punto de referencia artístico por excelencia y, si se trata de proponer un paralelismo entre la creación artística y la literaria, todo sucede entre los muros de la pinacoteca. El otro rincón es el estanque del parque del Retiro, al que acude Adam a trabajar en sus "traducciones» de Lorca. Allí es donde también se surtirá de hachís y desde donde verá tanto el transcurrir de las estaciones como las profundas marcas que dejará el atentado terrorista en la ciudad. Finalmente, la plaza de Santa Ana adquiere un papel muy destacado al convertirse en un auténtico 
mirador de la ciudad desde la claraboya de su casa a la que debe asomarse para poder ver la calle. Una visión panorámica, superficial y no comprometida que combina bien con su posición de observador no participante.

$\mathrm{El}$ «proyecto» en el que supuestamente debería trabajar Adam Gordon dota de sentido a su estancia en Madrid. Sin embargo, desde el principio deja claro que no tiene ningún interés en culminarlo ya que había sido simplemente una excusa que, en su momento, presentó para obtener la beca pero que en realidad no le interesa, que no tenía ni tampoco llegará a tener ningún conocimiento sobre la literatura a propósito de la Guerra Civil española, que supuestamente era el objeto de estudio que venía a investigar durante su estancia en Madrid:

What are you doing in Madrid, he said. Here I delivered a version of the answer I had memorized for my Spanish exam in Providence, a long answer composed by a fluent friend, regarding the significance of the Spanish Civil War, about which I knew nothing, for a generation of writers, few of whom I'd read; I intended to write, I explained, a long, research-driven poem exploring the war's literary legacy. It was an answer of considerable grammatical complexity, describing the significance of my project in the conditional, the past subjunctive, and the future tense (2011: 23).

Esta forma absolutamente superficial de referirse a un hecho tan dramático como es el de una guerra y, en especial, a la Guerra Civil española, que arrojó un número tan enorme de víctimas y cuyas secuelas aún resuenan en la sociedad española, pretende poner a la vez en discusión incluso el papel de los escritores estadounidenses en España. Al distanciarse, con la ironía desplegada sobre su propio trabajo, sobre la posibilidad de rastrear un legado literario de la Guerra Civil, se plantea una crítica, o al menos cierto desinterés por irrelevancia, a toda una «generation of writers, few of whom I'd read» (2011: 23). La obra de Hemingway, de John Dos Passos u otros poetas más implicados en la Guerra Civil como James Langston Hughes o el británico W.H. Auden, voluntarios en las filas republicanas, se despacha con un distanciamiento radical por parte de alguien que se supone ha obtenido una beca para estudiar ese asunto en detalle. A Adam Gordon no sólo no le interesa la representación artística y literaria de la Guerra Civil, sino que además la utiliza como una excusa para venir a Madrid, con lo que estaría banalizando aún más el acontecimiento.

Desde el comienzo, la novela se sitúa entre dos planos -el político y el literario, el real y el poético-, reflejados en el título. La referencia política es el atentado terrorista del 11-M, y la literaria, el poema «Leaving the Atocha Station» de John Ashbery, publicado en 1962 en su libro The Tennis Court Oath. El título de la novela funciona como una prolepsis que sugiere que la obra tendrá alguna relación con los atentados terroristas que tuvieron lugar en Madrid. La estación de trenes de Atocha no podría ser ya un lugar vacío de significación como aquel al que se refería Ashbery: "It meant nothing to me at the time except that I was in a strange city going somewhere» (Poulin: 245). Por el contrario, la estación de Atocha tiene una alta carga simbólica adquirida tras el atentado de 2004 tanto a nivel local como global. La novela avanza en las digresiones de su protagonista, sin que veamos aparecer nada que tenga que ver con el atentado, al punto de que 
llegamos a pensar que el título nos ha llevado por un camino erróneo. Al retrasar en el libro la aparición del momento del atentado se produce la postergación de un acontecimiento que, finalmente, resulta decisivo para interpretar todo lo sugerido anteriormente en la novela. Será precisamente en ese punto culminante y crítico, frente al estallido de las bombas y a la explosión de la realidad y de la historia, tal y como Adam lo relata, donde todas las elucubraciones autorreferenciales sobre el arte y su posibilidad de incidir en la realidad se desplegarán de forma intensa y explícita. Hasta ese momento, simplemente asistíamos a una narración meramente especulativa, al juego literario que describe la vida cotidiana de un escritor que se define a sí mismo como un impostor.

El efecto del título y el hecho de que la acción se desarrolle en Madrid facilitan que el lector interiorice la espera del atentado terrorista, aunque este no ocurra hasta muy avanzada la trama, casi cuando se empieza a creer que el título ha sido una trampa o que nos hemos equivocado y que, en realidad, la novela no va a plantearnos nada relacionado con aquel destacado acontecimiento. El título mismo representa el atentado mediante su localización en la estación de Atocha, lugar en el que se produjo un importante número de víctimas y que, por su carácter de estación central a la que se dirigían los trenes, terminó siendo el núcleo nominal de condensación del impacto del acto terrorista. Sin embargo, se sabe que el atentado tuvo lugar al llegar a la estación de Atocha y no al abandonarla, por lo que se incrementa así la sensación de que algo no va como debiera en la novela, que la pista que creemos certera desde el inicio puede que lleve por otro camino.

La novela apela inicialmente al acto poético representado en el poema de John Ashbery, abriendo un campo simbólico ligado a la escritura que cederá lugar, posteriormente, a la memoria de muerte y desolación que se generó tras el atentado terrorista de la mañana del 11 de marzo de 2004. La estación de Atocha, a partir de ese día, asociará su nombre a un momento determinado de la historia traumática y reciente de Madrid. Adam Gordon vive esa fusión entre arte y realidad. La novela cuestiona una y otra vez, jugando con el doble significado adquirido por Atocha, la posibilidad de volver a dotar de poesía a la estación de trenes de Madrid. En una entrevista que le hizo A. Fitzgerald en septiembre de 2011 a propósito de la publicación de esta novela, Ben Lerner expresará ese deslizamiento problemático entre lo real y lo poético:

I think ... that the title here evokes the aesthetic and the political and the troubled relation between them. The title names the site of the tragedy only to «leave» it; is there a turning away from the political toward poetry? Or is what's being left the poem -the virtual Atocha Station of poetry- for a place made actual by the irruption of the historical real? (Fitzgerald 2011: 303).

De esa manera, en esa tensión entre el acercamiento y el abandono de Atocha, el atentado se convierte, casi al final de la novela, en el detonante trágico que ofrece un sentido preciso a la pregunta sobre la posibilidad artística de incidir en el mundo real, de transformar la realidad. Ese giro obliga al lector a reinterpretar todo lo leído hasta ese momento, sin que se ofrezca una respuesta concluyente por parte del autor. El acto de terror, como ha señalado Michael Rothberg en su análisis sobre 
la interconexión entre lo público y lo privado en la literatura post-9/11, al centrarse sobre elementos profundamente afectivos más allá de tácticas políticas, posibilita que la literatura ofrezca un lugar privilegiado y efectivo para la reflexión sobre el significado del terrorismo y sobre cómo afrontar la experiencia vital posterior a los actos terroristas: "Aesthetics constitutes a bridging realm that connects subjective experience to larger collectivities» (2008: 124).

En el marco de ese fingir permanente que caracteriza al personaje de Adam Gordon, y tras una particular noche de locura en la que termina hospedándose con una amiga en el hotel Ritz después de haber cenado en Zalacaín, uno de los restaurantes más caros de Madrid, Adam se encuentra de frente con la historia, con los hechos, porque en ese momento ocurre el atentado del 11 de marzo de 2004 y mira a la calle desde la ventana de su habitación en ese lujoso hotel: "It was still early, rush hour. A few fire trucks passed by on El Paseo del Prado, sirens blaring. I was hungover, disoriented. Then several police cars passed. I leaned out the window and looked down the street, but couldn't see anything» (2011: 117). No deja de ser paradójico que estuviera en el hotel Ritz la mañana del atentado en un gesto por demás frívolo, superficial y absolutamente inútil: «When history came alive, I was sleeping in the Ritz» (2011: 158). No parece que sea un hecho fortuito que el lugar simbólico de un hotel de lujo conocido internacionalmente fuera el sitio desde el que las sirenas dirigiéndose a Atocha resonaran con más fuerza por lo que supone de choque con la realidad. Se trata de confrontar el plano de la banalidad de una vida de derroche sin sentido aparente con una tragedia suscitada por la intencionalidad de una acción terrorista.

Adam Gordon tendrá que admitir que algunas cosas inciden y cambian en la narración, en la poética, y que la actualidad se entromete en la literatura. Se siente incapaz de enfrentarse a los acontecimientos directamente en las calles de la ciudad, por lo que se recluye en su casa para ver el reflejo de los acontecimientos que sucedieron ese día de marzo a través de los medios de comunicación estadounidenses, a los que accede vía internet. Los media se apropian de los sitios y de las cosas que ocurren para construir la experiencia real: "It was almost ten. Surprised at how much time had passed, I opened a browser, called up the New York Times, and clicked on the giant headline. The article described the helicopters I could hear above me» (2011: 118). Lerner recrea ese momento como una especie de hibridación de lo que ocurre en las calles de Madrid y lo que ofrecen los medios digitales a miles de kilómetros del lugar del atentado. De esta manera, el punto físico de la ciudad en el que se concentra la violencia terrorista se ve constantemente desplazado por la persistente prevalencia de la actividad que desarrolla Adam Gordon en los espacios telemáticos.

I considered walking back to Atocha, but instead I opened El País in another window and the Guardian in a third. I sat smoking and refreshing the home pages and watching the numbers change. I could feel the newspaper accounts modifying or replacing my memory of what I'd seen; was there a word for that feeling? (2011: 119).

Adam prefiere seguir las noticias a través de internet. Aunque parece consciente de que podría formar parte de un momento histórico único, prefiere vivirlo 
mediado por la prensa y los diversos medios de información. Ante la imposibilidad de dotar de contenido por sí mismo a la experiencia, brota la necesidad de que la narración provenga del exterior. Se muestra así, una vez más, el marcado componente «glocal» de la novela desde el momento en que el personaje fusiona de manera indisoluble la representación visual que se le ofrece desde las grandes cadenas mediáticas y lo que sucede en las calles de Madrid.

Uno de los objetivos básicos de las acciones terroristas no es tanto actuar y dañar a un grupo de víctimas concretas y directas sino potenciar la repercusión mediática del atentado ("these attacks were 'made for TV'", le dice Teresa, la amiga y traductora de Adam), para conseguir así una ampliación enorme del número de víctimas potenciales que sufren el terror y que ven incrementar su sensación de inseguridad y su sentimiento de vivir en el seno de una sociedad del riesgo global. Una reflexión similar es la que plantea Gayle Rogers a propósito de "Didactic Elegy», un poema de Ben Lerner que aborda la temática del atentado del 11 de septiembre de 2001:

Lerner's meditation on 9/11 (or rather on images and depictions of 9/11) begins: «It is difficult to differentiate between the collapse of the towers/ and the image of the towers collapsing./ The influence of images is often stronger than the influence of events/ as the film of Pollock painting is more influential than Pollock's paintings.//» To speak in poetry of the mediation of $9 / 11$ is commonplace; to read these images through one of Pollock at work is a striking displacement of affect and a commentary on the nature of authorship and artistry that Lerner often interrogates (Rogers 2013: 222).

La intensidad emocional de la representación del atentado se combina con la narración del ambiente artístico madrileño, que se presenta en la novela como un retrato del esnobismo de una población de clase media alta, de ideología progresista, aunque despreocupada, a la que se sitúa siempre en fiestas hasta altas horas de la noche. Incluso se les ve así en los días posteriores al atentado aunque ahora incorporen a sus charlas, supuestamente trascendentes, las repercusiones políticas del atentado y sus inmediatas consecuencias: «There were a lot of people, Teresa and Rafa the only two I knew, smoking and drinking and talking animatedly about the protests and elections» (2011: 132).

La novela de Lerner muestra la distancia y la indiferencia con que viven unos personajes a los que se supone consternados por el ataque terrorista. Aunque la conmoción se hace presente en su participación en las manifestaciones que se sucedieron en las calles de Madrid, así como en las discusiones que mantienen, el espacio semiprivado de sus fiestas mantiene una estricta barrera frente a las molestias y ruidos de fondo que provoca el mundo exterior con su política, los atentados y las víctimas. El cinismo adquiere un carácter aún más destacado después de las bombas y se acentúa la imagen estereotipada y satírica de la beautiful people madrileña que no se ve afectada de manera directa por los atentados.

Las horas posteriores al acontecimiento son las que adquieren mayor relevancia en Leaving the Atocha Station. Debe recordarse que en Madrid inmediatamente después del atentado se produjo una inmensa corriente de solidaridad y atención a las víctimas como ocurriera anteriormente en Nueva York o, posteriormente, en 
Londres. Pero, además, en el caso español, se produjo una enorme discusión política provocada, principalmente, porque setenta y dos horas más tarde tendrían lugar unas elecciones generales. Prácticamente todos los agentes políticos trataron o parecía que trataban de utilizar los efectos emocionales del atentado como parte de la campaña electoral. Al día siguiente de las bombas se convocan en todas las ciudades españolas manifestaciones de repulsa al atentado, se incrementó la tensión entre los agentes políticos y, como consecuencia, se produjo un cambio electoral que previamente parecía muy improbable.

Para Lerner, el atentado de Atocha fuerza a definir la práctica artística frente al terrorismo y a la política, no sólo alrededor de la intervención directa del artista o escritor, sino también de los críticos y del público receptor. Un pasaje de la novela gira en torno a la noche del 12 de marzo, fecha en la que estaba programada la inauguración de una exposición de arte contemporáneo en una galería propiedad de un amigo de Adam Gordon. Frente a la duda sobre la conveniencia de seguir con el plan de la inauguración o cancelarla, Adam propone que se cubran los lienzos con un manto negro en recuerdo de las víctimas, «as a visual moment of silence». La propuesta es recibida con gran entusiasmo por sus amigos ya que ven en ella una forma de representar el duelo y la solidaridad con los afectados. Sin embargo, dicho acto de repudio al atentado propuesto por el propio Adam y que concita el beneplácito de sus amigos y del público en general se convertirá para nuestro personaje en la clara muestra de la mercantilización del arte y del profundo sentido individualista de los artistas, puesto que parece imposible pensar en una actitud solidaria desinteresada cuando los cuadros están cubiertos de negro, pero no así el nombre del artista y el precio. La mercantilización del arte conecta con la idea expresada por Lerner en "Damage Control. The Modern Art World's Tyranny of Price», un artículo que publicó en Harpers a finales de 2013, donde expone la incapacidad de los artistas y de los consumidores de arte para situarse fuera del mercado, de espaldas a la imposición de un valor mercantil al arte.

La novela está construida sobre el juego de la verdad y la falsedad, sobre las posibilidades de que el arte pueda ser o no un reflejo de la realidad, o que sea una herramienta de transformación social. Ahora bien, este juego narrativo se apoya en la memoria de un joven que vive alcoholizado o bajo los efectos del hachís o de algún tipo de psicofármaco, lo que nos advierte, desde el principio de la novela, que cualquier cosa que pudiera suceder o relatar no puede ser fiable ni tener una correspondencia directa con los hechos: «I left the hotel and walked into the sun. Or was it cloudy?» (2011: 117).

A pesar de la aparente ligereza con la que el narrador extranjero se enfrenta a la ciudad, finalmente la visión que nos muestra es dura y crítica porque para Adam Gordon pocas cosas o casi ninguna han cambiado en la ciudad después de los atentados. No es casual que al día siguiente de que se produjeran esos sucesos sus amigos españoles estuvieran debatiendo sobre el tema en el mismo espacio festivo en el que lo hacían las semanas anteriores. Pareciera que en el fondo no hubiera pasado nada a pesar de la conmoción inicial, o al menos nada esencial habría cambiado para un grupo de gente que, en principio, conformaría la vanguardia artística del momento. 
Lerner presenta una perspectiva crítica hacia la presión de determinados estamentos relacionados con la generación y reproducción artística, que instigan a los creadores para que ofrezcan una respuesta inmediata ante cualquier acontecimiento de índole política, forzando a que el artista se erija como conformador de opinión. En las páginas de la prensa de los días posteriores al atentado del $11 \mathrm{de}$ septiembre escribieron muchos escritores, pintores y músicos de reconocido prestigio para expresar su parecer sobre el acontecimiento, no precisamente desde el espacio creativo sino como comentaristas o conformadores de opinión. Lerner critica esta situación y rechaza esa demanda sobre los creadores, no porque considere que el arte no tenga nada que decir sobre la política, sino porque se opone a la forma que utilizan las sociedades mediáticas para convertir la fama de un personaje público en un aval para expresar opiniones sobre los más diversos ámbitos.

Adam Gordon debe enfrentarse, casi al final de la novela, con un importante compromiso en un acto organizado por la fundación Fulbright. Se trata de presentar, en su calidad de investigador sobre las representaciones literarias de la Guerra Civil española, sus opiniones a propósito del papel del arte ante el terrorismo en un Madrid todavía conmocionado por el atentado del 11-M. El esfuerzo que se ve obligado a hacer se presenta como un ejercicio de autorreflexión del personaje, que en un monólogo interior nos transmite de manera muy clara sus opiniones sobre la relación entre arte y política.

I tried hard to imagine my poems' relation to Franco's mass graves, how my poems could be said meaningfully to bear on the deliberate and systematic destruction of a people or a planet, the abolition of classes, or in any sense constitute a significant political intervention. I tried hard to imagine my poems or any poems as machines that could make things happen, changing the government or the economy or even their language, the body or its sensorium, but I could not imagine this, could not even imagine imagining it. And yet when I imagined the total victory of those other things over poetry, when I imagined, with a sinking feeling, a world without even the terrible excuses for poems that kept faith with the virtual possibilities of the medium, without the sort of absurd ritual I'd participated in that evening, then I intuited an inestimable loss, a loss not of artworks but of art, and therefore infinite, the total triumph of the actual, and I realized that, in such a world, I would swallow a bottle of white pills (2011: 45).

Este párrafo condensa buena parte del nudo central de la novela, en la que se cuestiona la utilidad de la poesía o del arte en general, si se concibe como un instrumento o una "máquina», en palabras de Lerner, para la acción política directa. Se presenta así un conflicto entre una posible forma de vivir la relación entre política y literatura que nos remite a una tensión profunda entre la insistente crítica a las diversas formas de la impostura artística e intelectual y una defensa desesperanzada de la necesidad última del arte.

En la novela, la mirada del extranjero sobre el acontecimiento que tiene lugar en el ámbito de lo local, aunque producto del conflicto global, está desprovista de una historia emocional individual vinculada de manera directa al atentado de Atocha. Cabría esperar que el personaje de la novela por el simple hecho de ser 
estadounidense viviera el atentado del 11-M con una carga emotiva extra por lo que significaría una especie de revival del 9/11. Sin embargo, la novela nos lleva por un camino muy diferente, alejada del trauma de los atentados, sin mayor resquicio de inseguridad o sensación de riesgo, pero sí con una insistente preocupación por el lugar y la responsabilidad del escritor y del artista en general en este tipo de situaciones «glocales».

La novela de Lerner pone en cuestión la necesidad de responder desde la expresión artística a cada acontecimiento político y a la forma en que se realiza. No plantea tanto la crítica al arte mismo cuanto a los artistas y a la forma en la que en nuestras sociedades se produce la circulación y el reconocimiento del arte desde un entramado de artistas, galeristas, escritores, críticos, etc. De esta forma, Lerner cuestiona la posibilidad de que tales grupos sociales pudieran ser capaces de responder de manera adecuada a problemas de la seriedad que comporta la vida política y social.

Lerner se distancia de los escritores norteamericanos de la Guerra Civil a los que supuestamente Adam Gordon estaba investigando. Sin embargo, allí mismo se sugiere la necesidad del arte para poder enfrentarse a la sensación de desasosiego y de desesperanza, para dotar de otros significados y abrir otras posibilidades en la consideración de un mundo que, de otra manera, parecería pétreo e inmodificable. Que en un marco de incertidumbre global otro mundo sea posible no es tarea inmediata para el arte, pero el arte puede contribuir a que nos demos cuenta de que el presente no es el único mundo posible. Que esta novela lo consiga es cuestión diferente, pero Lerner indirectamente parece decirnos que tampoco lo lograron aquellos escritores norteamericanos que llegaron a España y que narraron la Guerra Civil. Se produce así un intento doble de crítica a la responsabilidad política del escritor y a la tradicional novela de viajero norteamericano en Europa.

Recibido: junio de 2018; aCeptado: octubre de 2018. 


\section{BIBLIOGRAFÍA}

Barrio Marco, José Manuel (2004): «El viaje arquetípico-iniciático. El viaje como génesis y arquetipo cultural de la Literatura Norteamericana», en Francisco M. Mariño, y María Oliva Herrera, El viaje en la literatura occidental, Valladolid: Universidad de Valladolid, 179-208.

Fernández Santos, Elsa (2013): «Aquel día de marzo en que Madrid dejó de ser una fiesta», El Pais, Madrid, 13 de febrero: 43.

Fitzgerald, Adam (2011): «Ben Lerner», en Betsy Sussler, Bomb, Nueva York: Soho Press, 295-304.

Kiczкowsкi, Adriana (2016): "Glocalización in post- 9/11 literature. Burnt Shadows by Kamila Shamsie», Journal of English Studies 14: 125-136.

Lerner, Ben (2011): Leaving the Atocha Station, Minneapolis: Coffee House Press.

Lerner, Ben (2013): «Damage Control. The Modern Art World's Tyranny of Price», Harpers Magazine, Diciembre: 43-49.

Losa, J. (2013): «Algo he hecho mal si me elogian», El Público, 30 de enero. URL: https://www. publico.es/actualidad/he-hecho-mal-me-elogian.html; 18/10/2018.

Oоsтdjк, Diederik (2013): «Fulbright Poems: Locating Europe and America in the Cold War», en Ferdâ Asya (ed.), American Writers in Europe. 1850 to the Present, Nueva York: Palgrave MacMillan, 165-186.

Poulin, A., Jr. (1981): «The Experience of Experience: A Conversation with John Ashbery», Michigan Quarterly Review 20 (3): 242-255

Rogers, Gayle (2013): «An Interview with Ben Lerner», Contemporary Literature 54 (2): 219-238.

Rothberg, Michael (2008): «Seeing Terror, Feeling Art. Public and Private in Post-9/11 Literature» en Ann Keniston y Jeanne Follansbee Quinn (eds.), Literature after 9/11, Nueva York: Routledge, 123-142.

Thompson, Carl (2016): «Travel Writing Now, 1950 to the Present Day», en Carl Thompson (ed.), The Routledge Companion to Travel Writing, Nueva York: Routledge, 196-214.

Vogelzang, Robin (2013): “Homeland Strangeness': American Poets in Spain, 1936-1939», en Ferdâ Asya (ed.), American Writers in Europe. 1850 to the Present, Nueva York: Palgrave MacMillan, 141-164. 